\title{
PYHCOP CATI JIJÕ PJII - TERRITÓRIO GAVIÃO DO MARANHÃO
}

DIAS $^{1}$, Luciana de Oliveira - Juhen/Caxu'cwyj GUILETO $^{2}$, Diana Sansão - Jar GUARÁ $^{3}$, Edimara Bandeira - Ajcrun GAVIÃO ${ }^{4}$, Edivaldo Moreira - Toxwa GAVIÃO ${ }^{5}$, João Grossar Cardoso - Xyj Cry $\mathrm{CARDOSO}^{6}$, Joaquim - Eh'caryy $\mathrm{COSTA}^{7}$, Katiúscia Brito Teixeira da - Cu’tete/Tep Kaprik GAVIÃO ${ }^{8}$, Leonice Cardoso - Wacõo GAVIÃO ${ }^{9}$, Mara Lúcia Bandeira Martins - Amxyh GAVIÃO ${ }^{10}$, Marcélia Guará - Haprex TIMBIRA $^{11}$, Maria Barros - Hyn'Crii GAVIÃO ${ }^{12}$, Raquel Bandeira - Pynhyc GAVIÃO ${ }^{13}$, Suely Bandeira - Recwyj

1 Rede UFG/UFT/UFMA. Professora da Universidade Federal de Goiás.

2 Rede UFG/UFT/UFMA. Professora de Educação Básica.

3 Rede UFG/UFT/UFMA. Professora de Educação Básica.

4 Rede UFG/UFT/UFMA. Professor de Educação Básica

5 Rede UFG/UFT/UFMA. Professor de Educação Básica.

6 Rede UFG/UFT/UFMA. Professor de Educação Básica.

7 Rede UFG/UFT/UFMA. Professora da Universidade Federal de Goiás.

8 Rede UFG/UFT/UFMA. Professora de Educação Básica.

9 Rede UFG/UFT/UFMA. Professora de Educação Básica.

10 Rede UFG/UFT/UFMA. Professora de Educação Básica.

11 Rede UFG/UFT/UFMA. Professora de Educação Básica.

12 Rede UFG/UFT/UFMA. Professora de Educação Básica.

13 Rede UFG/UFT/UFMA. Professora de Educação Básica. 


\section{RESUMO}

Este artigo apresenta questões relacionadas ao Território Gavião, especificamente aquelas atinentes ao Povo Pyhcop Cati Ji, ou Povo Gavião. Esta marcação primeira é importante por consideramos que no Território Gavião não vive somente o Povo Gavião. Inicialmente nosso esforço foi apresentar o Território Gavião, que fora batizado de 'Terra Indígena Governador'. Para tanto descrevemos a população, a fauna e a flora do território, além de discutirmos processos de demarcação e re-demarcação. O objetivo foi textualizar para ampliar o conhecimento sobre algumas concepções e apropriações do território que são feitas pelos próprios Pyhcop Cati Ji. Como toda escrita produzida a partir de muitas mãos, cabeças e corações, esta também tenta traduzir impressões, sensações, experiências e saberes diversos que se complementam na realização do texto embora não o finalizem. Finalmente, ressaltamos que houve um enfoque em movimentos de demarcação e re-demarcação do território, o que nos direciona para um fechamento politizado da questão.

Palavras chave: Gavião. Conhecimento

\section{ABSTRACT}

This article presents questions related to the Gavião Territory, specifically those concerning the Pyhcop Cati Ji People, or Gavião People. This first marking is important as we consider that not only the Gavião People live in the Gavião Territory. Initially our effort was to present the Gavião Territory, which had been baptized as 'Indigenous Governor Land'. For such a purpose, we describe the population, the fauna and the flora of the territory, in addition to discussing processes of demarcation and redemarcation. The aim was to improve knowledge about some conceptions and appropriations of the territory that are made by the Pyhcop Cati Ji themselves. Like all writing produced by many hands, heads and hearts, it also tries to translate impressions, sensations, experiences and varied knowledge that complement each other in the accomplishment of the text, although it does not finalize it. Finally, we emphasize that there was a focus on demarcation movements and re-demarcation of the territory, which leads us to a politicized closing of the issue.

Key words: Gavião. Knowledge. 


\section{HAREN JATOJ}

Mam cohpe amnre reereh ehmpo cuu'cateh, ehmpo xu me pryhre me, ehmpo cateh mam, max ehnta'cym cohpe jõ'creh mejnymreh, my cohpe peh to hyycoo ne to peh re eh'cut ehmpoo xuu pyr re ne ehmpo xu to hyycoo to hane hã ne pryhre te hajyhr hã. Cwyr japiimy ehmpo ehnta ji amnre to moo. Eh'huc ehnta cym ca me hompoh ne me paapi pyhcop cati ji jõ pjii já'cre pex ne cohme cym me paa my ehmpo ehnta ji jamy. Mam mejpi pyhcop cati ji my hõ cateh xym me eh'tyx amjohmy to pohr jahyh ne me'cohne cym ajpen my hymcwar to ehjpa. Wa me jo pji cym cu ehnta ji japry jare pom pji cym cu ehnta ji cut wa mejpi pyh cop cati ji jy pin to pra pom mam cu cut mej quit ji me mejpohp xwy jy pin xy cutwa me ehjtyx jy pin to ehjpa cu jeh hee ne cu catyt ne favir. Eh'tyx mejpi pyhcop cati ji cym mejte amjohjahyhr xy a'pyhny ehmpo caxohw, pom me jõ amjohquehn cati ji ne pom me jõ pji cym ehmpo ehnta ji cohne caxohw me ajpen to eh'himpex pohr me, hyypin me, me hohjahir xy'ny ne pom ehmpo xu cacuuneh caxohw ne ehmpo cwy caxohw me'tyx ajpen to eh'himpex. Eh'tyx ehnta'cym me jõ pji cym ry'my mejpi pyhcop cati ji me, pryhjeh me, põ cati ji me, crepym cati ji me, Kariri me, Guajá me ne cohpe te hajyhr hã me a'poo ne me ajpen pjin ne hehxeh ne mejpa. Wa mejpi pyhcop cati ji ry'my jy'tuu to moo ne hamoh me a'pyhny to crehn tohw jahyh ne me jõ pji ehncrii re tohm ny my mecpi pa'heh cati ji my to pji camen prym. Ne ry'my mecte to mam mejpi pyhcop cati ji jõ pji hyhr tohm ny eh'huc par cacruu my ne funai cym cohpe hatox cym noore ne Brasehr cym funai te harcwa qui xyh'reh pyhcop cati ji me pryhjehre cati ji ajpen my eh'cacuc xym mecmy to pji hyhr tohw me pryhjeh jõ pji me ehjpeh caxir prym ne põ cati ji jõ pji te hajyhr max me ta my hatoj cym xym wa mejtyx ajpen cym pa tohm ny. Ne xwyre my eh'tyx pyhcop cati ji jõ pji ehncrii re tohm ny mecpi pa'heh cati ji te cohprõn ne meajpen my ne mecte a'pyhny creh cut me hohmre cryn qui me pji hyhr cut pra ne me ta'hã amjohcut pji jamy xym ne funai me federal cati ji me ibama ca cohmy taxmy cohpe peh to hyy coo ny hare wyr qui ryymy pra tohny my mecte me'cryn pji Jamyr xy'ny. Ehtyx ass. Wy'ty cateh xwyre me jõ pji ny eh'cacuc ne pom me pji jamy ehntaji my to projet jahyh qui cym mecmy amngõ,max cymy projet ehnta crynre. Ehmpo ehnta ji my mejpi pyhcop cati ji wa me ta'ny ehjcacuc ne me to amjohmy ehmpo jahyhr xy'ny xym ehmpo jy'tuu ne nee pji hyhr me pji Jamyr xy'ny peht noore ne ehmpo cwy te hajyhr hã ne mejmy eh'tyx creh cwy me amprac xyre te mejcym eh'pahym pex prym. 


\section{APRESENTAÇÃO}

Em consonância com o que apresenta Curt Nimuendajú (1946), começamos este texto chamando a atenção para o fato de que o nome "Gavião" foi atribuído a diferentes grupos Timbira que ocupavam a margem direita do Rio Tocantins, desde as proximidades do Rio Capim e Moju até as proximidades do Estado do Maranhão. A nominação Gavião está diretamente relacionada ao fato desses grupos utilizarem penas da ave na confecção de suas flechas.

Os Gavião são povos que compartilham do mundo Timbira (FERNANDES, 2010). Os povos Timbira localizam-se ao Sul do Estado do Maranhão, Sudeste do Estado do Pará e ao Norte do Estado do Tocantins. São falantes da língua Timbira da família Jê. Destacamos que fazem parte dessa família linguística: os Krahô, os Ramkokamekrá, os Apaniekrá, os Krikati, os Pikobyê, sendo que a estes últimos chamamos aqui de Pyhcop Cati Ji (todos esses localizados no estado do Maranhão), os Gavião Kyikatêjê, Parkatêjê e Akrãtikatêjê (no Pará) e os Apinayé (no Tocantins).

Neste texto lidamos com questões relacionadas ao Território Gavião, especificamente aquelas relacionadas ao Povo Pyhcop Cati Ji, aqui, por muitas vezes, chamado apenas de Povo Gavião. Adentremos, pois em uma tentativa de apresentar esse Território Gavião que fora batizado de 'Terra Indígena Governador'. Nosso esforço é organizar e levar a conhecer algumas concepções e apropriações do território que são feitas pelos próprios Pyhcop Cati Ji, com um enfoque em movimentos de demarcação e re-demarcação do território.

O Território Gavião foi demarcado e homologado em 1982 e têm 41.644 mil hectares de terra. Está localizado no sul do estado do Maranhão e é considerado uma das menores áreas demarcadas de todo o Brasil. Nesse Território Gavião existem atualmente 11 aldeias e vale destacar que há mais cinco aldeias Guajajara dentro do Território Gavião. Parte da área Gavião é composta por cerrado, mais especificamente "cerradão", devido ao seu porte mais alto e fechado daquele que é convencionalmente encontrado pelo Brasil; e mata de galeria, que são formas de vegetação que acompanham cursos d'água, bem como ambientes de drenagem em geral.

Dentro da área há uma estrada estadual, a MA 122, que liga o município de Amarante ao município de Arame. Há também estradas irregulares que viabilizam os deslocamentos que se fazem 
necessários. A MA 122 tem trazido uma série de problemas para o Povo Gavião, dentre os quais destacamos aqui a invasão de madeireiros, de caçadores e de outros exploradores que utilizam a estrada para transitar por dentro do Território Gavião e entre as aldeias Gavião.

A flora é exuberante e dentro dessa área indígena tem muitas frutas nativas, tais quais bacaba, bacuri, buriti, pequi, juçara também conhecida como açaí - e merindiba, que é um fruto quase desaparecido, mas de fundamental importância para a alimentação dos animais silvestres, e que por isso mesmo tem muita significância para o Povo Gavião, pois atrai animais para as proximidades. Essas, e tantas outras frutas, têm colaborado para a manutenção de hábitos alimentares e conformado uma culinária específica do Povo Pyhcop Cati Ji.

Assim como a flora, a fauna presente no Território Gavião também é rica e diversificada, há muitos animais, tais quais: caititu, cutia, paca, catingueiro, veado mateiro e vários outros que também compõem o cardápio tradicional do Povo Gavião. Entretanto, nas últimas décadas eles têm diminuído em número e a caça tem sido cada vez mais limitada.

No que se refere às limitações do Território Gavião, parte do limite da reserva é marcada por um riacho chamado 'Maribondo'. Esse riacho tem grande importância, porque, além de colaborar para a delimitação da área, estampando na paisagem que do outro lado do riacho não é área, compõe um cenário de beleza e saúde para o povo que ali vive.

O Território Gavião carece de proteção, defesa e valorização. Por essa e outras razões os indígenas Gavião passaram a fazer parte do Programa PrevFogo, do IBAMA - Instituto Brasileiro do Meio Ambiente e dos Recursos Naturais Renováveis. Esse programa tem colaborado com a proteção da Terra Indígena Gavião e tem sido protagonizado pelos próprios Gavião, que zelam pela preservação e proteção da fauna e da flora da área.

De acordo com o Censo Demográfico 2015, do IBGE Instituto Brasileiro de Geografia e Estatística, atualmente vivem 1300 pessoas dentro do Território Indígena Gavião. Em média existem aproximadamente 140 pessoas na Aldeia Riachinho, 110 na Aldeia Rubiácia e quase 300 pessoas na Aldeia Governador. 


\section{Demarcação do Território Gavião}

O processo de demarcação e homologação do território Gavião ocorreu em 1982 com aproximadamente 41.644 hectares de terras. O número estimado de indivíduos Gavião que habitam esse território é de 1.300 Pyhcop Cati Ji (Gavião).

Observamos que, antigamente, no território Gavião havia recursos naturais e abundância e variedade de fauna e flora suficiente para toda a população. As pessoas da comunidade pescavam, caçavam e coletavam frutos sem nenhuma dificuldade, pois todos os recursos necessários estavam fartamente disponíveis no território Gavião.

Mas, a partir do momento em que os invasores, como madeireiros, caçadores, fazendeiros e outros interessados em nossa terra começaram a vir para nosso território, notamos o aumento do desmatamento das florestas, desequilíbrio ecológico de vários tipos, extinção de animais e plantas. Ocorrem também plantios e extrações de madeira clandestinamente e queimadas criminosas.

Temos a necessidade de conhecer nosso próprio território com o objetivo de preservá-lo para as futuras gerações de índios Gavião. Além disso, dentro dos nossos limites territoriais podemos manter o equilíbrio entre homens e natureza com o objetivo de preservar nossa terra das influências externas negativas, que, entre outras coisas prejudicam nossa cultura e costumes, e destrói o meio ambiente em que partilhamos em comunidade.

Acreditamos que através da educação podemos ensinar aos nossos jovens sobre nossos direitos sobre nosso território e principalmente a necessidade de cuidar bem dele para a continuidade da nossa cultura e do nosso povo. Em outras palavras devemos conhecer para preservar.

\subsection{Histórico de constituição das aldeias na Terra Indígena Governador}

O antigo Posto Indígena na Aldeia Governador, na época do Serviço de Proteção ao Indígena, teve um papel muito importante durante um período de conflitos com os moradores do entorno do território onde vive o povo Gavião. O Posto Indígena acolheu a Aldeia Riachinho, a Aldeia Vereda Bonita, a Aldeia Canto Martins e a São 
Felix. Os conflitos ocorriam, porque a Terra Indígena Governador não era demarcada. Assim, os invasores, como madeireiros e caçadores, tentavam tomar a terra de nossos antepassados, criando conflitos que permanecem mesmo depois da demarcação da Terra.

Naquela época as aldeias foram atingidas por epidemias trazidas por "brancos", como uma grande moléstia que atingiu a Aldeia Riachinho, onde morreram várias pessoas. Com isso todos foram levados para a Aldeia Governador. A Aldeia Vereda Bonita foi deslocada para Governador devido a um ataque que sofreu de um pistoleiro, que destruiu e incendiou a Aldeia. Os moradores do Canto Bom foram deslocados, porque queriam assistência e acesso a Políticas Públicas. O mesmo aconteceu com os moradores da Aldeia São Felix.

No decorrer dos anos o número de pessoas aumentou e as formas de organizar a comunidade sofreram alterações. Alguns moradores começaram a consumir bebida alcoólica e uma série de problemas começou. As discussões aumentaram e as decisões do cacique já não eram mais respeitadas. A partir disso iniciou-se um processo de retorno dos moradores a suas antigas aldeias. Algumas delas receberam novos nomes e outras foram surgindo.

A primeira aldeia a deixar Governador foi a Aldeia Vereda Bonita, que recebeu o nome de Aldeia Rubiácea. Dela outra divisão deu origem à Aldeia Água Viva, à Aldeia Canto Bom e à Aldeia Novo Marajá. Depois a Aldeia Riachinho deixou Governador. Outra divisão deu origem á Aldeia Nova e à Aldeia Monte Alegre.

Atualmente as aldeias Gavião estão distribuídas em onze aldeias, sendo as mais recentemente constituídas a Aldeia Bom Jardim, a Aldeia Bom Jesus e a Aldeia Dois Irmãos, cada uma com seu cacique e suas formas de organização social interna. Os lugares sagrados para o povo Gavião estão localizados em aldeias antigas, cemitérios e rios.

As antigas aldeias são sagradas porque trazem muitas lembranças de nossos antepassados, onde faziam suas moradas. As construções eram feitas com madeira, que demoravam anos até precisarem ser substituídas e com palha, retirada da floresta.

As aldeias Gavião, em geral, se constituem por um pátio central onde ocorrem as celebrações, rituais e reuniões, circundado pelas casas e atrás delas são cultivadas as roças. Há também cemitérios que se encontram mais afastados das casas. Essas são as características mais marcantes de como os Gavião formam suas aldeias. 


\subsection{Manejo da terra no Território Gavião}

As roças são feitas e compartilhadas em grupo. Embora as roças sejam cultivadas em casas separadas, toda a comunidade se mobiliza para fazer a roça para uma determinada família. Consta que, antigamente, as roças eram totalmente comunitárias ocupando um lugar que não era uma casa em particular, mas uma área comum decidida em grupo. Agora funciona em um sistema de troca de serviços entre as famílias.

Alimentos tradicionais como milho, batata doce, inhame e mandioca são culturas recorrentes nas roças familiares. Estes alimentos são a base da alimentação do povo Gavião. Ocorre o manejo periódico, usualmente de três em três anos, com o cuidado de preservar e não desgastar o solo. Nos últimos anos a mudança do clima tem afetado a produtividade, pois a colheita destes e outros produtos têm sido cada vez menores.

\subsection{Manejo da água no Território Gavião}

A água, naturalmente, constitui um importante elemento para o território e para o povo Gavião. Nestas terras, embora não haja rios, existem riachos, brejos e lagoas de onde são pescados traíras, carás e mandis que fazem parte da alimentação dos Gavião. Os peixes se tornaram menos fartos ao longo dos anos. Entretanto, ainda é possível, no período de secas, pescar alguns peixes, a constar em meados do mês de setembro.

As águas de tonalidade vermelha vistas de longe são límpidas e refrescantes, servem de recuperação das forças após uma corrida de tora ou protagonizam momentos de lazer e relaxamento para a comunidade. Alguns dos riachos mais frequentados pelo povo Gavião são Cu'jehhee nas proximidades da Aldeia Riachinho e Cu'catyt nas imediações da Aldeia Governador. O riacho do Faveira se encontra bem próximo da Aldeia Rubiácea.

\section{A população Pyhcop Cati Ji (Gavião)}

O povo Gavião possui uma cultura própria e tem várias organizações dentro da aldeia. No nosso território, no Maranhão, existem também outras etnias bem próximas a nós, como os 
Guajajara. Acontecem muitos casamentos interétnicos e outros povos acabam compondo nosso território.

Dentro das nossas aldeias temos nossos costumes e tradições compartilhados pelas famílias e passados de geração em geração. Atualmente percebemos que os jovens não têm interesse por entender a importância de conhecermos nosso território e não perder este conhecimento no futuro.

Dentre as organizações Gavião dividimos responsabilidades e tarefas como preparação de festas culturais, pesca, caça, colheita de frutos nativos, manutenção da roça dentre outras. Em nosso território outras etnias estão presentes nas próprias aldeias. O exemplo são os casamentos interétnicos com Guajajara, Timbira, Krikati, Kariri, Guajá e com não indígenas também.

A importância de conhecer é para cuidar. Por isso devemos ensinar nossos jovens alunos sobre nosso território, do que ele é composto e como podemos cuidar dele para que o Brasil e o mundo saibam que os Gavião existem e têm seu próprio território.

\subsection{População atual no território Gavião: alguns desafios}

De acordo com o censo de 2015, a população dentro do território Gavião é de 1300 pessoas, divididas em:

- 11 aldeias Gavião: Governador, Rubiácea, Riachinho, Monte Alegre, Água Viva, Doze Irmãos, Bom Jesus, Canto Bom, Nova Marajá e Bom Jardim;

- 5 aldeias Guajajara: Faveira, Borges, Nova Jibóia, Nova Jurema e Barriguda. A população Guajajara, presente na Terra Indígena Governador - Gavião, conta com 200 pessoas entre adultos, jovens e crianças. As relações sociais atualmente entre eles são, em geral, amigáveis graças a alguns casamentos interétnicos e relações de amizade. Porém no começo não era bem assim. Foi necessário entrar em acordo para que esses novos moradores respeitassem o modo de vida do povo Gavião.

Entretanto, essas presenças são também preocupantes por causa do número de aldeias dentro da nossa Terra Indígena e estamos em expansão. Daí a grande necessidade da ampliação da mesma. Além disso, alguns desacordos entre lideranças ocorrem em relação à venda ilegal de madeira, para além das necessidades da aldeia, por parte de outras etnias, mas não todas. A expansão da população de outras etnias causa também a reivindicação dos mesmos pela nossa 
terra e eles se afirmam dentro do nosso território, o que gera muitas discussões. Esses moradores não-Gavião não têm intenção de sair ou mudar para algum outro lugar.

A grande questão agora é discutir a chegada de novos moradores, ampliação das aldeias e da população de outras etnias e a perda do território pelo povo Gavião. Deste modo, quem está assentado tem o direito de continuar a viver em nossas terras. O que não desejamos é a chegada de mais outros povos e o aumento da presença de outras etnias ao ponto de perdermos nossa terra.

Em instâncias maiores com a Fundação Nacional do Índio - FUNAI, em Brasília, discute-se a criação de novas aldeias para os Guajajara em outras áreas e evitar rivalidades entre os grupos. A negociação está em curso atualmente, mas não está sendo fácil avançarem as discussões assegurando direitos à terra.

Os chamados "Guardiões", voluntários indígenas Gavião, com o apoio da associação Wy’ty Cateh, estão detectando degradação da área Gavião, muita poluição e venda ilegal de nossos recursos e as outras aldeias não têm a mesma consciência que temos de respeito por nossa terra.

Esta é a situação que enfrentamos no momento em relação à população que ocupa o território. Temos respeito e relações de afeto e amizade com outras etnias, mesmo quando eles não nos aceitam muito bem em suas aldeias e famílias, mas temos o direito sobre nosso território e queremos ser respeitados e reconhecidos por isso.

\section{A Fauna característica do Território Gavião}

A terra indígena Governador tem aproximadamente $41 \mathrm{mil}$ hectares de terras demarcadas e homologadas. Porém, anteriormente existiam muitos animais nesta área, como a ema, o tatu canastra, o papagaio e a arara vermelha.

Observamos a cada ano que passa que esses e outros animais que nos são tão familiares estão correndo grande risco de extinção, principalmente pela ação de caçadores, madeireiros e exploradores de toda ordem, afetando a rotina natural e o equilíbrio de várias espécies como as citadas acima. Na terra indígena Gavião se encontram também muitas aves, como tucano, jacu, curica e papagaio. Caça também, como preguiças e a sucuri, que mora aos pés do buriti. Nós chamamos de brejo e riacho.

De acordo com o relato de Sueli Gavião, "Minha mãe comentava que no caminho para outras aldeias se viam muitas emas andando pelo 
cerrado. Hoje em dia os meus filhos já não assistem a essa cena porque essa espécie está quase extinta em nossa região, os homens caçando pelo cerrado encontravam os ovos delas abandonados nos ninhos e os levavam para casa para o seu consumo.

Antigamente, se aproveitava tudo da ema. Desde a carne toda até a banha, que serve para ser misturada com a massa de urucum. Mesmo assim, usar tudo da ema não era capaz de fazer desaparecer todas de uma vez. Visitei o Zoológico de Goiânia junto com a minha filha e a turma da minha sala, lá ela viu a ema do cerrado pela primeira vez, contei para ela que a ema existia em nosso cerrado e que hoje não está presente com frequência, tanto que ela ainda não conhecia".

Outro caso interessante que podemos ilustrar é o da arara ou Pýn na língua Gavião. Antigamente havia muitas araras no nosso território, mas agora não existem mais na floresta e suas penas são importantes para a fabricação de adornos para festas e rituais. Temos muitas dificuldades em encontrar a ave em seu habitat natural, fazendo com que, muitas vezes, tenhamos que negociar suas penas em aldeias de povos vizinhos.

Devido à entrada de caçadores ilegais, as aves foram retiradas em grande número e as que ficaram não se reproduziram o suficiente em nossa área. As que resistiram aos ataques de caçadores também tiveram problemas em achar árvores grandes, que foram desmatadas. Podemos dizer que na área Gavião praticamente não tem mais arara.

Quando os Gavião realizam as festas tradicionais, temos que sair para procurar e comprar as penas de araras nos territórios Guajajara, Canela, Krahô, e outros. Em algumas festas tradicionais a presença da pena da arara é muito importante, principalmente o rabo, como por exemplo, a festa de Ceveiro, exclusiva para as meninas.

Nós, do povo Gavião, precisamos nos articular em desenvolver um projeto em acordo com a comunidade, para criar e cuidar de araras dentro do território Gavião. Consideramos ser uma tristeza pensar que no futuro bem próximo a única representação que teremos dos animais são desenhos e fotos. Assim as futuras gerações podem não mais conhecer a natureza como eu e meus antepassados já conhecemos.

\subsection{Animais domésticos nas Aldeias Gavião}

Além dos animais das matas, a paisagem das aldeias Gavião também é composta pelos que transitam entre os espaços e aqueles que estão inseridos quase que exclusivamente no interior das aldeias. Fáceis de serem vistos em volta das casas e pelos arredores, 
os animais domésticos do povo Gavião interagem em sua maioria para fora dos limites das casas. São cães, gatos, galinhas e galos, bois e vacas, tartarugas e macacos, que, mediante variados graus de interação, estima e pertencimento, compõem do dia-a-dia das aldeias do povo Gavião.

Embora grande parte dos cães e gatos não seja bem-vinda portas adentro ou que sejam considerados animais de animal de estimação, como acontece com frequência em outros contextos sociais brasileiros, esses típicos animais domésticos estão bem próximos ao convívio das pessoas nas aldeias. Em geral procuram abrigo e alimento no entorno das casas e circulam livremente entre os quintais, perturbam galinhas e interagem com crianças, sem que recebam nomes ou referências a possíveis donos deste ou aquele gato ou cachorro.

Neste mesmo cenário, galinhas e galos circulam entre os demais moradores em seu habitual andar frenético entre ciscadas e bicadas para lá e para cá. Os galos tratam logo de sinalizar bem cedo o início de um novo dia com seus imponentes e robustos cantos que reverberam por toda aldeia e para todos. Convivendo no mesmo espaço, porém com distanciamento bem maior, vacas e bois estão às voltas em bandos ou separadamente e possuem donos. Em geral são ofertados ao abate durante comemorações ou celebrações específicas e degustados por todos.

Entretanto a proximidade ou estima por um bicho específico pode ser observada no caso de tartarugas e macacos de pequeno porte, por exemplo. Estes dois ilustram bem a relação que se estabelece entre animais e pessoas para além da mera coexistência ou necessidade. A fim de evitar que se embrenhem mato adentro, as tartarugas são presas a um barbante atado ao pé de algum tronco ou banco e são ali cuidadas e alimentadas, ao passo que também interagem com os demais no mesmo espaço.

Por fim, a imagem capturada na aldeia Governador expressa bem a afetividade que emerge desta relação. Nela uma menina segura zelosa e orgulhosa seu bicho de estimação sob os olhares e mãos curiosas de outras crianças. Afirma ter lhe dado um nome e um canto para dormir em sua rede em clara demonstração de mútuo afeto e parceria.

Assim, os animais domésticos ou de estimação são parte constituinte da vida nas aldeias e do povo Gavião e estão dispostos, em sua maioria, livremente pelos espaços. Estes animais domesticados se encontram longe das coleiras, grades e cercados comuns entre os bichos em outras localidades do país, sobretudo as cidades. Embora em liberdade, existem limites para a circulação de cachorros, gatos, galinhas e tartarugas para o interior das casas. 


\section{A Flora presente no Território Gavião}

Aflora do território Gavião é composta parte de Cerrado e parte de mata viva, já que faz parte da Amazônia Legal. Ela ainda existe em boa parte, mas alguns problemas com fogo e desmatamento por parte de alguns invasores não-indígenas colocam nossa área em risco.

O povo Gavião colhe frutos nativos como bacaba, buriti e juçara e também pesca os peixes para seus alimentos. Além disso, existem muitas plantas medicinais tradicionais do Povo Gavião muito utilizadas para problemas na vesícula e myyjõ 'quen, que é usado para problemas de estômago. Temos também a casca de aroeira, muito útil para inflamações de útero e feridas no corpo e até fraturas, colocando-se a cinza em cima do membro afetado. Outro exemplo interessante é o broto-do-mato, ou paca catetehxu em Gavião, que é para o tratamento do diabetes, comendo-se o fruto.

O urucum também. Tanto o fruto quanto a raiz e as folhas são importantes. Quando fervidos ajudam a curar de icterícia em crianças e dores de cabeça em adultos. Todo o conhecimento sobre essas plantas nos é passado pelos anciãos que utilizavam delas para manter a saúde em nossas aldeias. A cura através das plantas não é de conhecimento dos nossos jovens que recorrem aos remédios químicos. Muitas vezes, eles acabam usando as plantas medicinais quando percebem que os remédios químicos não fazem efeito.

Em nosso território existe uma variedade grande de plantas que dão flores ou frutos e compõem a riqueza de nossa flora. Entretanto, ocorrem também muitas queimadas criminosas e retirada ilegal de árvores e isso ameaça todo nosso ecossistema. Existem também plantações irregulares em nosso território que não foram feitas por nós indígenas, mas que mesmo assim fazem uso de nossos recursos naturais.

\subsection{O Cerrado e a Mata de Galeria}

Trataremos agora do lugar onde atualmente se encontra o Povo Pyyhcopcatiji e todas as aldeias do grupo Jê. No cerrado colhemos as frutas nativas para consumo. A exemplo, temos pequi, bacuri, mangaba, puçá, araçá, cajuí e catolé da chapada e bruto da chapada. Não podemos esquecer também do oiti e do murici.

O Cerrado também nos beneficia com a matéria prima para fazer remédios naturais extraídos de raízes, sementes e folhas tais como sementes de sucupira folha e casca da mesma, barbatimão 
candeia, pau de leite, tingui brabo, mangabeira batata da chapada, raspa de pau pombo e catuaba. A ema, a seriema, perdiz, bambus, e vários pássaros grandes e pequenos vivem no Cerrado. O preárato que come coquinho da chapada também tem no Cerrado o seu habitat natural.

Existem caças que só são encontradas no cerrado. São elas, a raposa, o tatu china, o peba amarelo, o tatu da chapada, o tatu rabo de couro, o veado campeiro, e o veado catingueiro da chapada. A variedade de cobras do Cerrado inclui a cobra cipó, a cascavel, a cobra do rabo fino, a coral e a jararaca.

No Cerrado (chapada) contamos também com vários tipos de coco, o cocoré tucum rasteiro, o coco babaçu o catolé. Todas essas espécies de coco são consumidas, e suas raízes e folhas são aproveitadas. As folhas servem para cobrir as casas, e as raízes, para remédios naturais dos anciões. Os tipos de cerrado são: campo limpo, campo sujo e cerra vereda. Cerra, por sua vez, é onde se encontram as caças, como o peba de casca amarela, o veado catingueiro, e variados tipos de árvores rasteiras como o puçá e as piçarras, que os cupê usam para construir casas.

O Campo limpo é caracterizado pelo capim rasteiro, a presença do cajuí, da seriema, da ema perdiz, do lambu e vários pássaros de espécies diferentes. Neste local se localizam os frutos de mangaba. As flores na primavera embelezam o ambiente com suas cores variadas, tipo bem-me-quer e mau-me-quer e o tucum rasteiro.

Já no campo sujo todos os tipos de árvores podem ser encontradas e são denominadas lajeado. Tanto o bacuri e o pé-debruto são abundantes e é também o local de esconderijo das cobras cascavéis venenosas.

O período compreendido de julho a setembro marca o período de queimadas que não poupam o capim, os animais, nem as árvores. Isso já é de conhecimento das comunidades indígenas, embora pouco se possa fazer em relação a isso. Contudo, hoje em dia existem os guardiões do Programa PrevFogo, que tentam proteger as nossas chapadas mesmo frente a todas as dificuldades. Percebemos que nem todos estão conscientes dos prejuízos das queimadas e ateiam fogo na mata em dias muito quentes. Falaremos mais sobre os Guardiões mais a frente.

As Veredas compreendem um lugar cheio de igarapés, que chamamos de 'olho d'água' e onde apanhamos buriti, juçara, bacuri, bacaba e folhas de banana - brava, e também favorecem nossas 
pescarias. A paca, por exemplo, só é encontrada nesse lugar. Jacarés e jabuti d'água podem ser pescados aqui. Enfim, as Veredas formam um cenário muito bonito e apreciado pelo povo Gavião.

Em seguida, temos a Mata de Galeria, que compreende a área nativa, onde vários tipos de árvores estão dispostos. Temos ipê, taúba, jatobá, amarelão, aroeira e outras espécies comuns de árvores. Esta mata também favorece a caça de caititu, da onça pintada e da vermelha, do macaco, da guariba, do quati e outros tipos de caças menores.

É de fundamental importância lembrar que essa é uma área muito visada e disputada pelos não indígenas. Isso por causa da variedade de espécies de árvores e caças. Aves como papagaio, arara e tucano fazem parte deste cenário. A jandaia, o jacu, o tiú, o jabuti da mata e a preguiça também estão nesse território. É de onde também tiramos embira de embiruçu que colocamos no pacará, por exemplo.

\section{Processo de re-demarcação da Terra Indígena Governador}

O termo 'ampliação' não nos parece muito adequado em relação à re-demarcação das terras Gavião. Preferimos, pois, nos referir a essa situação com a palavra 'revisão'. Essa revisão de limites visa à parte deixada de fora pelos antropólogos que fizeram a demarcação atual. Segundo os anciãos, o povo Gavião tinha uma área muito maior que englobava os municípios de Buritirana e Sítio Novo. Essa área que foi demarcada às pressas foi em função de conflitos com os não indígenas que estavam nas proximidades do território Gavião. Ocorreram até mortes de índios Gavião e não houve consulta aos anciãos, muito menos estudos antropológicos sobre a área.

Atualmente o Povo Gavião reivindica junto à FUNAI, considerando-se o novo estudo do território, uma redefinição e a ampliação dos limites do Território Gavião. O relatório já foi elaborado. Contudo infelizmente encontra-se tramitando na justiça sem alcançar maiores avanços.

Com o aumento do número de indivíduos, consequentemente o aparecimento de outras aldeias divide espaço com fazendas e invasões de madeireiros e fazendeiros que nos trazem muitos problemas. Além disso, a presença de outros grupos indígenas que se dispersam pelo Território Gavião em larga escala coloca em risco a posse da terra pelos Gavião. Justifica-se esta preocupação porque os mesmos também reivindicam esse espaço como se fosse também 
deles originalmente. Assim sendo, essa ação também aparece como empecilho e até mesmo é impeditiva ao andamento regular de todo o processo.

Dentre os cerca de oito processos a respeito dessa revisão e que levam à homologação estamos em fase muito inicial, o que torna a evolução muito lenta, sobretudo pela ausência de parceiros que apóiem nessa causa.

A população de Amarante tem em seu imaginário que o Governo tem interesse em re-demarcar essa área e utilizamos isso como uma estratégia de proteção que nós encontramos para não entrarmos em disputa com as pessoas desta cidade e dificultar ainda mais as relações sociais.

Consta que o mapa desta revisão já existe e amplia o território Gavião consideravelmente. Então, este é um assunto muito importante e que deve ser discutido com toda comunidade para tentar a melhor forma de continuar vivendo em harmonia com as outras pessoas que não sejam Gavião e ao mesmo tempo preservando nossa terra e nossa natureza.

\subsection{Pycop Jõ'Pji Jamyr Cati Ji: Os Guardiões do Território Gavião}

A iniciativa de conhecer e proteger nossas terras de forma coordenada partiu da própria comunidade e das lideranças indígenas do Povo Gavião através da agência implementadora, Wyty Cate, em parceria com a FUNAI. A equipe dos Guardiões é composta de 37 pessoas responsáveis por percorrer as áreas e reportar as irregularidades e problemas para podermos discutir as ações em grupo.

O objetivo dos Guardiões é o de realizar o monitoramento constante das terras indígenas com recursos provenientes do PBA, e este acordo está em conformidade com os caciques e demais lideranças Gavião. Durante o trabalho de monitoramento pelo Pji Jamyr Cati Ji (Guardiões), muitas irregularidades são percebidas e interrompidas, como por exemplo, a apreensão de 100 mancos e 120 esticadores de 8 metros cada sendo negociados ilegalmente na terra indígena Governador.

Quando iniciou esse programa os Pji Jamyr Cati Ji logo perceberam a dimensão da devastação e do desmatamento praticado 
principalmente pelos madeireiros, caçadores e coletores em geral. As queimadas também estão muito presentes nos limites das áreas indígenas Gavião, que, futuramente, vão impactar o ecossistema e a sobrevivência do nosso povo.

Além disto, os indígenas sofrem pressões das cidades e moradores vizinhos. Quando ocorre um conflito pelo nosso espaço com madeireiros, fazendeiros ou outros, a intervenção da FUNAI só ocorre em casos gravíssimos ou mesmo de morte. Normalmente temos que lidar com as diferentes ameaças e pressões sozinhos, por isso os Guardiões têm um papel fundamental na nossa proteção e preservação.

Os resultados dos trabalhos de monitoramento estão sendo positivos e realizados de maneira transparente para que todos os indígenas possam observar, analisar, criticar as ações dentro da TI Governador. Mais do que nunca nosso povo precisa preservar todo território e saber reivindicar ações e atuação da FUNAI, do IBAMA, da Polícia Federal e das demais instituições que devem garantir e promover a proteção, a conservação e a sustentabilidades dos recursos naturais das terras indígenas, assegurando a integridade do patrimônio Gavião, para melhoria da nossa qualidade de vida.

Os Pji Jamyr Cati Ji representam uma iniciativa criada por nós e precisam de apoio e estímulo de todo o Povo Gavião. As reuniões envolvem toda comunidade e esse monitoramento ajuda a preservar o território para as gerações futuras e para todos nós.

Embora não haja uma articulação forte entre todos os Gavião, existem pessoas que contestam o nome de Terra Indígena Governador e isso gera discussões ainda muito isoladas, porém de grande relevância. Consta que a FUNAI registrou as terras com esse nome coincidindo com o nome da Aldeia Governador. Os favoráveis à mudança do nome alegam que ele só representa uma única aldeia e está em idioma português.

Houve duas tentativas frustradas de mudança de nome. Entretanto as discussões continuam de maneira ainda informal e isolada, ouvidas "ao vento" nas palavras da acadêmica Wacõo, que já participou de algumas rodas de conversas sobre este assunto e garante que falta "coragem" para levarem esse assunto a instâncias maiores nas comunidades do povo Gavião.

Os defensores dessa mudança apresentam argumentos interessantes de que o nome na língua Gavião os fortaleceria e contemplaria todas as aldeias unindo o povo. As burocracias que 
envolvem essa questão são muito ressaltadas durante as discussões, mas existem pessoas que acreditam que é válido.

\section{CONSIDERAÇÕES FINAIS}

A partir dos estudos realizados coletivamente percebemos que a questão do território é fundamental para pensarmos o passado, o presente e o futuro de um povo. A partir do registro de nosso conhecimento sobre nossa própria terra podemos nos fortalecer e reivindicar nossos direitos sempre que nos sentirmos invadidos ou violados.

Pudemos notar a partir da fala dos anciãos, nossos interlocutores neste estudo, que muitas mudanças no território aconteceram desde que eram muito jovens, não só pela invasão e exploração das terras, mas também pela diminuição dos recursos disponíveis. Isto quer dizer que vários animais e plantas não existem mais ou são difíceis de serem achados em nossas áreas.

Entendemos também que conhecer de maneira mais aprofundada nosso próprio território permite identificar nossas próprias riquezas naturais e preservá-las. As plantas, as sementes, os frutos, as raízes e os diversos animais são parte importante das nossas vidas, pois estão presentes em nossos adornos, rituais, alimentação e saúde, enfim em nossa existência.

Muito importante é discutir com os mais jovens Gavião sobre o território, pois eles são a futura geração de Gavião que vão dar sequência à nossa cultura e modo de viver. Desta forma, este texto pode ser utilizado como material didático e de orientação em sala de aula e em espaços de discussão e debate sobre o Território Gavião.

Ao demonstrarmos com essa escrita que os Gavião possuem um território e existem como povo, assumimos a responsabilidade de ensinar aos jovens e crianças sobre os direitos e deveres acerca do Território Gavião. E, para ensinar, precisamos aprender a preservar e a zelar a terra, vivendo em harmonia com o meio ambiente.

Temré!

\section{REFERÊNCIAS}

ANCIÃOS e ANCIÃS Gavião. Entrevistas realizadas pelos acadêmicos/as Gavião e Timbira, na Aldeia Riachinho. Novembro, 2015. 
FERNANDES, Rosani de Fátima. Educação Escolar Kyikatêjê: novos caminhos para... Dissertação de Mestrado. Programa de Pós-Graduação em Direito. Universidade Federal do Pará: Belém, 2010.

MELATTI, Júlio César. Ritos de uma Tribo Timbira. São Paulo: Ática, 1978.

NIMUENDAJÚ, Curt. The Eastern Timbira. University of California.Publications in American Archaeology and Ethnology, vol. 41, 1946. 
